\begin{tabular}{|l|l|}
\hline Title: & $\begin{array}{l}\text { Design versus Assessment of Concrete Structures Using Stress Fields and } \\
\text { Strut-and-Tie Models }\end{array}$ \\
\hline Authors: & Muttoni A., Fernández Ruiz M., Niketic F. \\
\hline Published in: & ACI Structural Journal \\
\hline DOI & $10.14359 / 51687710$ \\
\hline $\begin{array}{l}\text { Volume: } \\
\text { Pages: }\end{array}$ & $\begin{array}{l}\text { V. } 112 \text { No 5 } \\
\text { pp. 605-616 }\end{array}$ \\
\hline City, country: & Farmington Hills, USA \\
\hline Year of publication: & 2015 \\
\hline Type of publication: & Peer reviewed journal article \\
\hline
\end{tabular}

Please quote as:

Muttoni A., Fernández Ruiz M., Niketic F., Design versus Assessment of Concrete Structures Using Stress Fields and Strut-and-Tie Models, ACI Structural Journal, V. 112 No 5, Farmington Hills, USA, 2015, pp. 605-616. 


\title{
Design versus Assessment of Concrete Structures Using Stress Fields and Strut-and-Tie Models
}

\author{
by Aurelio Muttoni, Miguel Fernández Ruiz, and Filip Niketić
}

Stress fields and strut-and-tie models are widely used for design and assessment of structural concrete members. Although they are often used in the same manner for both purposes, developing suitable stress fields and strut-and-tie models for the design of a new structure or for assessment of the strength of an existing one should not necessarily be performed following the same approach. For design, simple load-carrying models in equilibrium with the external actions can be considered. From the various possibilities, those leading to better behavior at serviceability limit state and to simple reinforcement layouts should be selected (or a combination of them). For the assessment of existing structures, however, avoiding unnecessary strengthening (or minimizing it) should be the objective. Thus, simple stress fields or strut-and-tie models are to be iteratively refined whenever the calculated strength of the member is insufficient with respect to the design actions. This can be done by accounting for kinematic considerations to calculate the higher possible strength of the member accounting for its actual geometry and available reinforcement (allowing to calculate the exact solution according to limit analysis). In this paper, the differences between the two approaches for design and assessment are clarified and explained on the basis of some examples. A number of strategies are comprehensibly presented to obtain suitable stress fields and strut-and-tie models in both cases. The results of exact solutions according to limit analysis (developed using elastic-plastic stress fields) are finally compared to 150 tests of the literature showing the consistency and generality of the presented approaches.

Keywords: assessment; design; limit analysis; stress fields; strut-andtie models.

\section{INTRODUCTION}

Currently, most codes for structural concrete are oriented to design of new structures. Yet assessing the strength of existing structures (and their retrofitting, if necessary) is becoming more and more a relevant task for structural engineers. This is influencing codes of practice, which start incorporating new concepts related to life cycle design ${ }^{1}$ or evaluation and assessment. ${ }^{2,3}$ Grounding codes of practice on physical models reveals to be an efficient manner to cover both aspects, as design can be performed by assuming safe and simple hypotheses, which can be refined if necessary for an assessment. ${ }^{4}$

Although the same physical models can be used for design and for assessment, the use that is made of these models can be very different depending on what type of analysis is performed. The design of a new structure should cover its ability to carry the design actions (safe solution at ultimate limit state [ULS]) as well as its suitable behavior under service loads (satisfactory behavior for cracking or deflections for instance at serviceability limit state [SLS]). For assessment of an existing structure, however, it is only normally sufficient to investigate on its ultimate strength because the SLS behavior can be usually checked in-place by inspections and accounting for the experience of end users (provided that the actions remain unchanged). ${ }^{5}$ In these cases, if a conventional analysis shows an insufficient level of safety, the estimate of the strength of the structure needs to be more refined (accounting for other potential load-carrying actions) because this might avoid unnecessary retrofitting or minimizes it.

Another significant difference between a design and an assessment refers to the concept of most suitable or optimum solution. To achieve an optimum design, it is normally cost that is to be optimized. In common practice, the best solution is the one that respects ULS and SLS criteria and that allows minimizing costs (referring to amount of materials but also time for design and construction). In this sense, selecting simple solutions that require a slightly higher amount of reinforcement but that are simpler to design, reinforce, control, and cast are usually preferred. When performing an assessment of a critical structure, cost should also be optimized. Normally, this is done if any strengthening is avoided or at least minimized. In some cases, the requirements at ULS can be ensured by means of simple analyses. In these cases, there is no need to perform more refined investigations. ${ }^{4}$ However, whenever an insufficient level of safety is found with simple analyses, the use of more refined or advanced analysis methods is thus plenty justified as they allow considering for all potential load-carrying actions and provide an accurate estimate of the actual strength of the member.

With reference to structural concrete, the use of stress fields and strut-and-tie models provide a physically consistent frame to design new structures and to assess their strength. They are both based on the lower-bound theorem of limit analysis. Limit analysis can be considered as a method to calculate the failure load of a member considering a perfectly plastic behavior of materials. ${ }^{6}$ According to Drucker, ${ }^{7}$ the lower-bound theorem of limit analysis can be written for reinforced concrete members as follows: "If an equilibrium distribution of stress can be found in the concrete and the steel which is nowhere tensile in the concrete and is

ACI Structural Journal, V. 112, No. 5, September-October 2015

MS No. S-2014-178.R2, doi: 10.14359/51687710, received October 14, 2014, and reviewed under Institute publication policies. Copyright (C) 2015, American Concrete Institute. All rights reserved, including the making of copies unless permission is obtained from the copyright proprietors. Pertinent discussion including author's closure, if any, will be published ten months from this journal's date if the discussion is received within four months of the paper's print publication. 


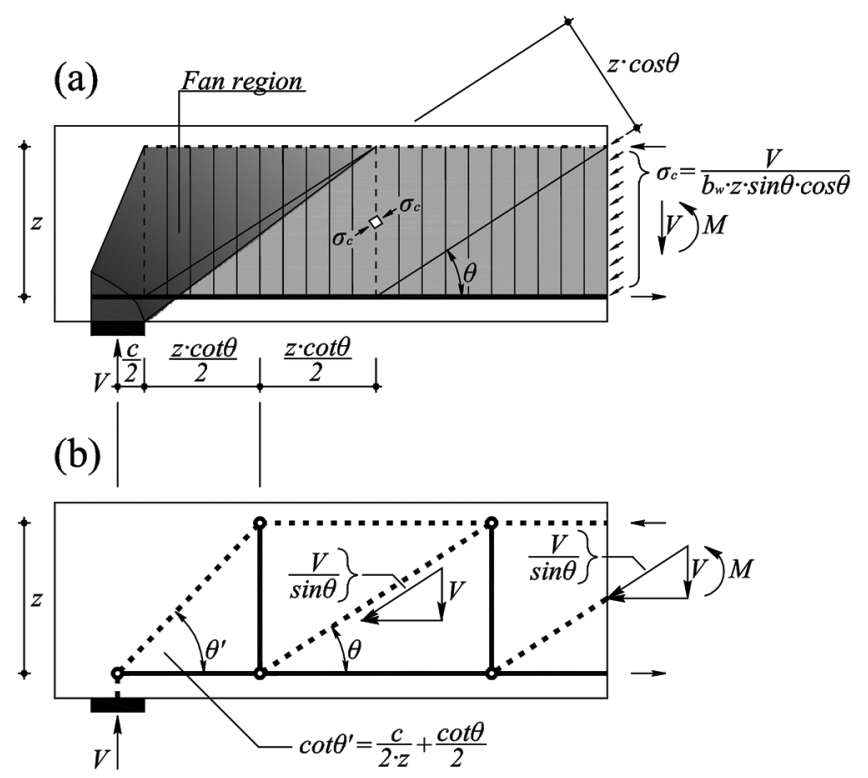

Fig. 1-Stress fields and strut-and-tie models: (a) stress field for beam near support region; and (b) corresponding strutand-tie model.

everywhere at or below yield, the structure will not collapse or will just be at the point of collapse." It can be noted that in this formulation, concrete crushing is intended as yielding. This means that models for structural members according to strut-and-tie and stress fields methods, by definition, might underestimate the strength of the member (provided sufficient ductility of the member). The stress field method ${ }^{8}$ allows determining a licit state of stresses in a structural concrete member in equilibrium with a given set of actions; refer to Fig. 1(a). On that basis, the stresses developing in the concrete can be calculated (Fig. 1(a)) as well as the amount and location of the tensile reinforcement. The resultants of the stress field can further be used to develop a strut-and-tie model, providing a view of how the forces are carried within the member (Fig. 1(b)). The angles of the struts and ties as well as their forces can be consistently calculated on the basis of the stress field (refer, for instance, to the angle $\theta^{\prime}$ of the strut corresponding to the fan region, different from the value at the region where the compression field develops at constant angle $\theta$ and allowing to consider the actual support dimensions). Because both methods are based on the lowerbound theorem of limit analysis, they can be used to obtain safe solutions for design of new structures (equilibrium solutions respecting the yield criteria of the materials).

Limit analysis has also an upper bound theorem which can be very useful for calculating the load-carrying capacity in the case of assessment of existing structures. According to Drucker": "The structure will collapse if there is any compatible pattern of plastic deformation for which the rate of work of the external loads exceeds the rate of internal dissipation." When a stress field satisfies both the lowerand upper-bound solution, it is named as the exact solution according to limit analysis (unique if, as usually assumed, the yield surface is convex and the increment of plastic strains is normal to the yield surfaces of the materials ${ }^{9}$ ). For instance, Drucker showed that for the stress field presented

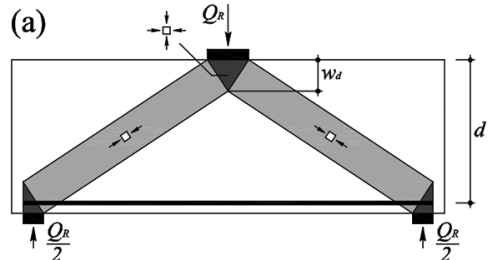

(b)
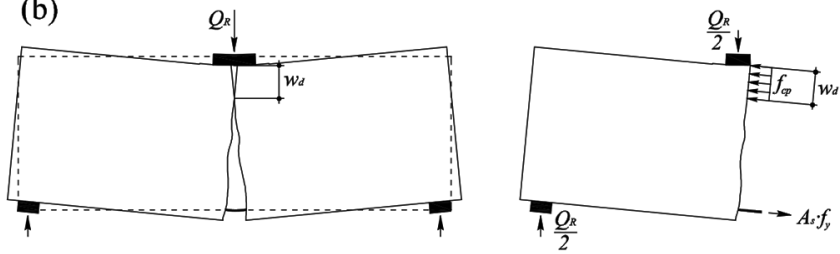

Fig. 2-Investigation of beam under point load according to Drucker ${ }^{7}$ : (a) stress field; and (b) corresponding failure mechanism.

in Fig. 2(a), the structure can develop a licit failure mechanism (Fig. 2(b)) and is thus an exact solution (if the structure has sufficient ductility). Such a solution can be considered as the best potential stress field that can be developed for the assessment of an existing structure, as it is the one providing the largest strength of all potential lower bounds (safe solutions). Even if the strengthening cannot be avoided with the most refined estimate of the strength (exact solution), it can be minimized, providing significant potential savings to the operation.

In this paper, various strategies for developing suitable stress fields and strut-and-tie models for design and assessment of structural concrete members are presented and discussed with reference to some examples. The concepts are explained from a general perspective, although the application will be limited to two-dimensional cases (walls and beams). The accuracy of limit analysis is finally compared to available test data showing the consistency of the approach and its generality.

\section{RESEARCH SIGNIFICANCE}

This paper presents a discussion on the conceptual differences for the approaches that should be followed when performing the design of a new structure and the assessment of an existing structural member using stress fields and strut-and-tie models. For structural concrete (members with sufficient ductility), it is shown that limit analysis and its theorems can be consistently used for both purposes, and a number of tailored procedures (both using hand-made or computer-based procedures) are presented and discussed. The suitability of limit analysis is finally validated in a systematic manner by assessing the strength of test results on a wide number of structural members and failure modes.

\section{STRESS FIELDS AND STRUT-AND-TIE MODELS}

As previously explained, stress fields and strut-and-tie models share a common root as they are grounded on limit analysis. However, the methods and their application have a number of differences, each of them presenting some specific advantages. 
(a)

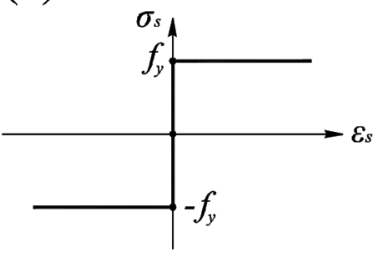

(b)

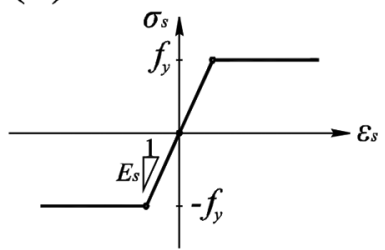

(c)

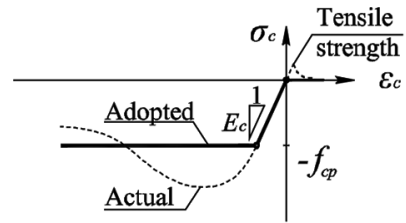

Fig. 3-Behavior of materials: (a) rigid-plastic steel; (b) elastic-plastic steel; and (c) elastic-plastic cracked concrete.

Truss models, which can be considered ancestors of strut-and-tie models, were first developed on the basis of intuition for beams. ${ }^{10,11}$ Truss models allowed calculating a possible equilibrium solution where the inner forces of a truss developing inside the concrete element equilibrate the external actions (refer, for instance, to Fig. 1(b)). Compression forces were supposed to be carried by concrete and tension by the reinforcement (thus allowing consistent design). Truss models were later developed and generalized. In Stuttgart, ${ }^{12-14}$ it was shown that there was no need for the load-carrying model to be an actual truss and that funicular models in equilibrium with the applied actions were suitable, leading to the development of the strut-and-tie models. These works also opened an approach where the location of the strut and the ties was proposed to be inspired on the elastic uncracked stress field of a member. Such an approach was very convenient at that time because elastic uncracked internal forces could be calculated with available procedures (photoelasticity or linear FEM). The consistency of strutand-tie models with the lower-bound theorem of limit analysis was also investigated, ${ }^{14}$ as well as automatic procedures for developing suitable strut-and-tie models. ${ }^{15}$

The stress fields originated on a different basis, based directly on the theory of plasticity. This theory can be grounded on the works of Gvozdev (published in English in $1960^{16}$ ), who first formulated consistently the concepts of the yield surface, upper- and lower-bound solutions, and the flow rule. The theory was later developed and was used in 1961 by Drucker $^{7}$ to develop a stress field for a simply supported beam under point load (Fig. 2(a)) or distributed loading. The stress fields were later developed particularly in Denmark ${ }^{6}$ and Switzerland, ${ }^{17}$ leading to a consistent method for design of concrete structures.

For their use in practice, each method has its advantages. Using them in a combined manner is probably the most suitable approach for the designer, as both are in fact different manners of expressing the same physical reality. For instance, stress fields provide a detailed description of the stress state of the member (Fig. 1(a)). They allow determining the width of the compression fields or struts, thus calculating the stresses developing in the concrete to compare them to the concrete strength (Fig. 1(a)). Also, they allow understanding and identifying the location where smeared reinforcement is to be arranged. The development of stress fields is thus particularly useful for detailing (required space for the struts, reinforcement bents, stresses in the nodal regions) and to account for variable angle of the compression fields (fan or constant-angle compression fields). Despite these advantages, a complete development of the stress field, particularly in non-critical regions, may be time-consuming and unnecessary. This is the reason why combining stress fields with strut-and-tie models (Fig. 1(b)) is usually advantageous. The strut-and-tie models can in fact be considered as a simplification of the stress fields, accounting only the resultants (forces) of the stress fields. This allows a simple calculation of the internal forces and of the required reinforcement at the ties (concentrated or smeared), the critical concrete regions requiring, however, a more detailed stress field analysis.

\section{USE OF LIMIT ANALYSIS FOR DESIGN AND ASSESSMENT OF STRUCTURAL CONCRETE}

Application of limit analysis to structural concrete requires a number of considerations. A detailed analysis of the topic can be consulted elsewhere. ${ }^{6,8,18}$ In the following, reference will be made to members with sufficient reinforcement to control cracking and avoid crack localization.

With respect to reinforcing steel, it can be modeled as a rigid-plastic (Fig. 3(a)) or elastic-plastic (Fig. 3(b)) material. Concrete is, however, more complex to model as a perfectly plastic material due to its brittle behavior in compression and to the development of cracking in tension (Fig. 3(c)). Suitable approaches for limit analysis neglect its tensile strength and consider the material as rigid-plastic or elastic-plastic in compression with a plastic plateau strength $f_{c p}$

$$
f_{c p}=f_{c} \cdot \eta_{f c} \cdot \eta_{\varepsilon}
$$

where $f_{c}$ refers to the uniaxial compressive strength of concrete; and $\eta_{f c}$ and $\eta_{\varepsilon}$ are strength reduction factors accounting, respectively, for the brittleness of concrete and the influence of transverse cracking on the strength of the compression field. The former can be evaluated as ${ }^{19}$

$$
\eta_{f c}=\left(\frac{f_{c 0}}{f_{c}}\right)^{1 / 3} \leq 1.0
$$

where $f_{c 0}$ is a reference compressive strength that can be set to $30 \mathrm{MPa}$ (4300 psi) for normal-strength concrete, as proposed in Reference 1. With respect to the latter factorthe influence of transverse cracking on the compressive strength - it has been thoroughly investigated by several researchers. For instance, Vecchio and Collins ${ }^{20}$ proposed a suitable value for coefficient $\eta_{\varepsilon}$ as follows

$$
\eta_{\varepsilon}=\frac{1.0}{0.8+170 \cdot \varepsilon_{1}} \leq 1.0
$$



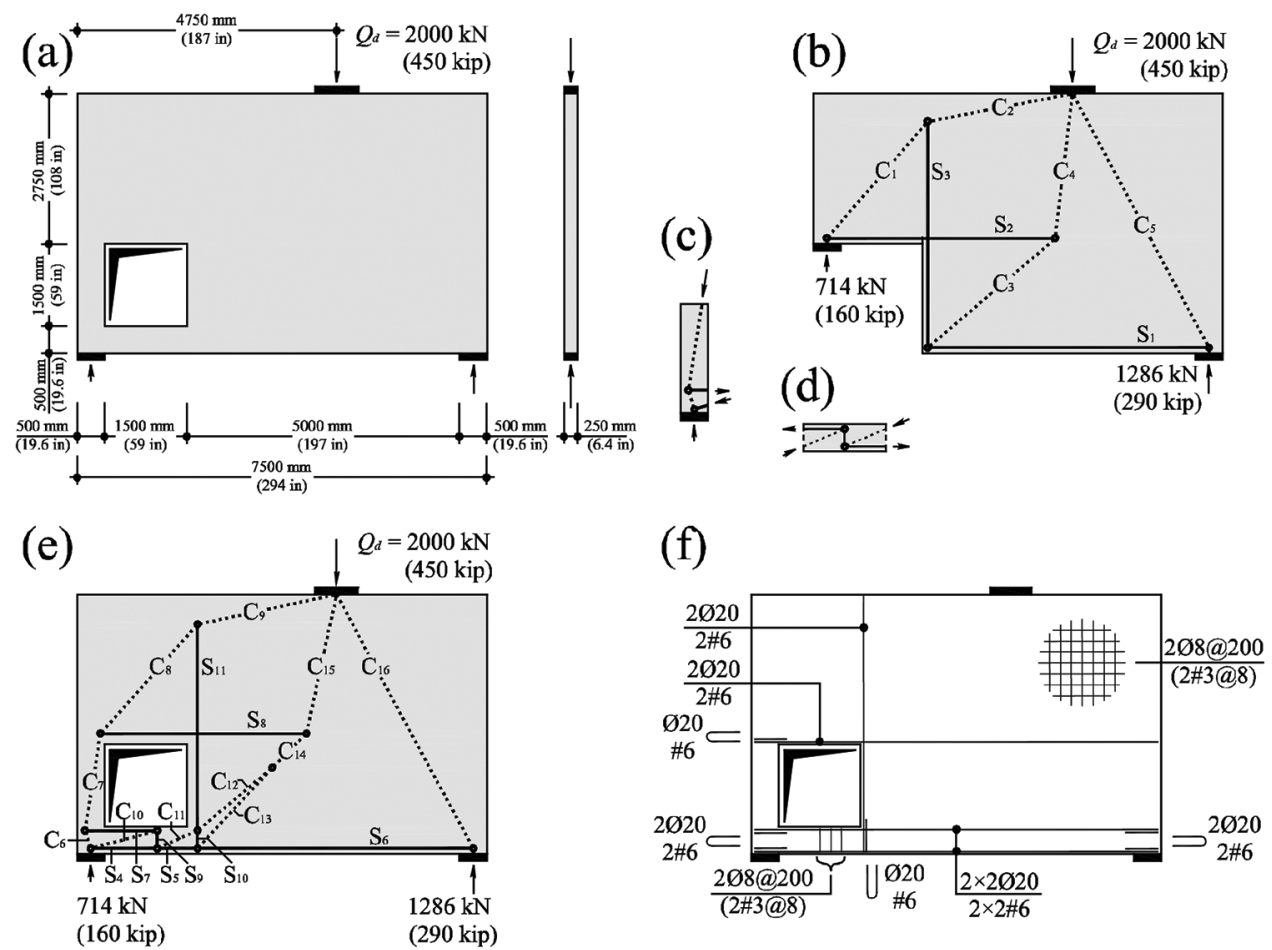

Fig. 4-Development of equilibrium solutions based on simple load-carrying models (values provided in Table 1): (a) investigated member; (b) analysis as dapped-end beam; (c) and (d) consideration of contribution of column and beam around opening; (e) combined model; and (f) required reinforcement to carry loads and welded wire of minimum reinforcement.

where $\varepsilon_{1}$ refers to the principal transverse strain of concrete. This strain can be calculated when the materials are assumed to behave with an elastic phase prior to reaching their plastic plateau. ${ }^{18}$ When the materials are assumed to behave in a rigid-plastic manner (typically useful for hand-made calculations), the value of parameter $\eta_{\varepsilon}$ is set depending on the cracking state and orientation ${ }^{1,8}(1.0$ for uncracked concrete, 0.8 for concrete cracked parallel to the loading direction, 0.6 for diagonally cracked concrete as in shear, and 0.4 for large plastic strains in two directions as shear near plastic hinges). The influence of other phenomena on the compressive strength of concrete can also be accounted; for instance, the presence of ducts ${ }^{21,22}$ or the influence of sustained loading. ${ }^{23}$

\section{DESIGN OF NEW STRUCTURES}

As previously explained, design of new elements should be performed to obtain safe structures at ULS with satisfactory behavior at $\mathrm{SLS}^{24}$ and with a reinforcement layout as simple as possible for its construction and control. Developing suitable stress fields or strut-and-tie models to that aim can be performed following a number of strategies. Four possibilities are presented hereafter, but others (or combinations of them) can also apply. The selection of the most suitable approach for a given case is usually decided by the designer, depending on his or her experience, the complexity of the problem, and the required level of accuracy of the analysis.

\section{Load-carrying models inspired on experience or on similar cases found in literature}

Very often, design of a new structural member can be performed by assimilating it to a known case. This, for instance, is shown in Fig. 4(a) (beam with an opening). This case can be designed in a simple manner by considering it as a dapped-end member, allowing for calculation of the necessary reinforcement (Fig. 4(b) and Table 1). If necessary, the load-carrying model can be enhanced by considering, for instance, the contribution of the coupling beam and column of the member (at left and below the opening), and incorporating them into the load-carrying model (Fig. 4(c) through (e) and Table 1). This allows simple design of the main reinforcement of the element; refer to Fig. 4(f) (calculations performed with a design yield strength of the reinforcement equal to $435 \mathrm{MPa}$ [63 ksi]). This reinforcement is usually completed with a minimum smeared reinforcement for crack control and to allow for spreading of concentrated loads ${ }^{14,25}$ (refer to the welded wire reinforcement in Fig. 4(f)).

\section{Load-carrying models inspired on deviated thrust lines}

An alternative manner to the previous approach consists on drawing the ideal thrust lines necessary to carry the forces to the supports (Fig. 5(a) and Table 2) regardless of the actual geometry of the member. Then, the compression struts are to be deviated (by placing of a suitable reinforcement) so as to remain within the available concrete (Fig. 5(b) and Table 2). This method has been acknowledged as a general and suitable manner to develop stress fields. Its use however requires sometimes a number of iterations to avoid four potential problems:

- Zones without reinforcement where tensile stresses are expected. This is, for instance, the situation presented in Fig. 6(a). In this case, the primary tension tie is located above the opening and large flexural cracks may develop in an unsuitable manner below it (Fig. 6(b)). Even if a 
Table 1-Forces obtained using strut-and-tie models in Fig. 4

\begin{tabular}{|c|c|c|}
\hline \multirow[b]{2}{*}{ Strut $(\mathrm{C})$ or tie $(\mathrm{S})$} & \multicolumn{2}{|c|}{ Forces } \\
\hline & $\mathrm{kN}$ & kip \\
\hline $\mathrm{C}_{1}$ & -946 & -213 \\
\hline $\mathrm{C}_{2}$ & -632 & -142 \\
\hline $\mathrm{C}_{3}$ & -911 & -205 \\
\hline $\mathrm{C}_{4}$ & -597 & -134 \\
\hline $\mathrm{C}_{5}$ & -1460 & -328 \\
\hline $\mathrm{S}_{1}$ & 691 & 155 \\
\hline $\mathrm{S}_{2}$ & 620 & 139 \\
\hline $\mathrm{S}_{3}$ & 593 & 133 \\
\hline $\mathrm{C}_{6}$ & -665 & -149 \\
\hline $\mathrm{C}_{7}$ & -638 & -143 \\
\hline $\mathrm{C}_{8}$ & -844 & -190 \\
\hline $\mathrm{C}_{9}$ & -576 & -129 \\
\hline $\mathrm{C}_{10}$ & -322 & -72 \\
\hline $\mathrm{C}_{11}$ & -207 & -47 \\
\hline $\mathrm{C}_{12}$ & -248 & -56 \\
\hline $\mathrm{C}_{13}$ & -591 & -133 \\
\hline $\mathrm{C}_{14}$ & -837 & -188 \\
\hline $\mathrm{C}_{15}$ & -606 & -136 \\
\hline $\mathrm{C}_{16}$ & -1460 & -328 \\
\hline $\mathrm{S}_{4}$ & 99 & 22 \\
\hline $\mathrm{S}_{5}$ & 289 & 65 \\
\hline $\mathrm{S}_{6}$ & 691 & 155 \\
\hline $\mathrm{S}_{7}$ & 311 & 70 \\
\hline $\mathrm{S}_{8}$ & 461 & 104 \\
\hline $\mathrm{S}_{9}$ & 83 & 19 \\
\hline $\mathrm{S}_{10}$ & 433 & 97 \\
\hline
\end{tabular}

Table 2-Forces obtained using strut-and-tie models in Fig. 5

\begin{tabular}{c|c|c}
\hline \multirow{2}{*}{ Strut $(\mathrm{C})$ or tie $(\mathrm{S})$} & $\mathrm{k}$ & Forces \\
\cline { 2 - 3 } & $\mathrm{kN}$ & $\mathrm{kip}$ \\
\hline $\mathrm{C}_{1}$ & -994 & -223 \\
\hline $\mathrm{C}_{2}$ & -1460 & -328 \\
\hline $\mathrm{S}_{1}$ & 691 & 155 \\
\hline $\mathrm{C}_{3}$ & -634 & -143 \\
\hline $\mathrm{C}_{4}$ & -845 & -190 \\
\hline $\mathrm{C}_{5}$ & -575 & -129 \\
\hline $\mathrm{C}_{6}$ & -644 & -145 \\
\hline $\mathrm{C}_{7}$ & -871 & -196 \\
\hline $\mathrm{C}_{8}$ & -606 & -136 \\
\hline $\mathrm{S}_{2}$ & 510 & 115 \\
\hline $\mathrm{S}_{3}$ & 510 & 155 \\
\hline
\end{tabular}
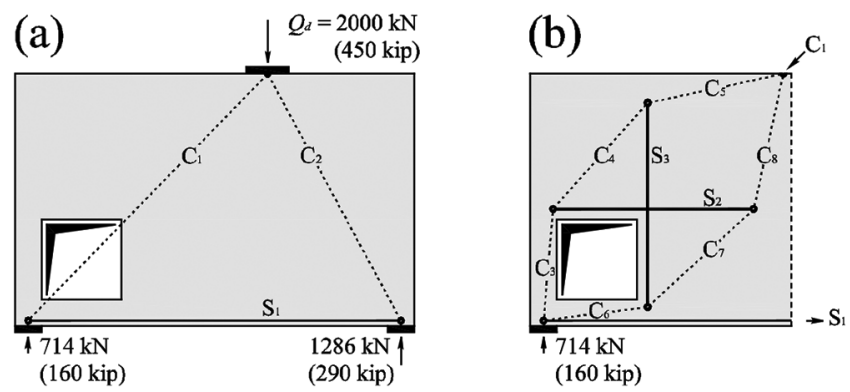

Fig. 5-Load-carrying models inspired on deviated thrust lines (values provided in Table 2): (a) funicular strut-and-tie model; and (b) deviation of left strut to account for presence of opening.

reinforcement for crack control is placed below the tie, significant crack widths in region "A" of Fig. 6(b) are required to activate the primary tie. To avoid such cases, Muttoni et al. ${ }^{8}$ proposed to account for the kinematics of the element to avoid regions where cracking develops in an uncontrolled manner. In the case of Fig. 6(b), it will consist of analyzing qualitatively the crack pattern of the member (Fig. 6(b)) and adapting the reinforcement layout to have a more suitable response (shifting the tie below the opening; for example, Fig. 5(a) and (b)). Alternatively, investigation of the tension zones of the uncracked stress field of the member might be useful to this respect. ${ }^{14}$

- The angle between the struts and the ties should be checked (region "B" of Fig. 6(b)). When no compatibility conditions are accounted (assuming, for instance, a rigid-plastic material behavior) and if no transverse reinforcement is available, the angle between the struts and the ties should usually be considered larger than or equal to 45 degrees. ${ }^{8}$ In the presence of transverse reinforcement, the angle between the struts and the ties can be reduced, but it is suggested not to reduce the angles below 20 to 25 degrees. This limit is grounded ${ }^{26}$ on the fact that, otherwise, the state of strains of the member become rather incompatible (with tension in the reinforcement and compression strains in the concrete developing at a low angle) requiring large tensile strains as well as crack widths to develop, which potentially reduces the value of coefficient $\eta_{\varepsilon}$ below the conventional thresholds ( 0.6 in this case). This is the reason why, for flat angles of the compression field, analyses based on elastic-plastic material properties accounting for cracking lead to more accurate results..$^{21,22}$ An upper limit to this angle can be necessary in case of potential brittle anchorage failures.

- Unsuitable nodal regions should be avoided. Generally, TTT (tension-tension-tension) nodes are unsuitable in strut-and-tie and stress fields models. ${ }^{8}$ This is justified by the large crack widths potentially developing in the nodal region, leading to very low values of the strength-reduction factor $\eta_{\varepsilon}$. Whenever a TTT nodal region is present in a load-carrying model, it is preferable to modify the topology to avoid such kind of node, or prestressing of at least one tie is required. Other nodal regions such as 
(a)

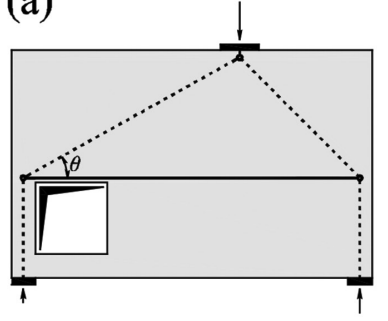

(c)

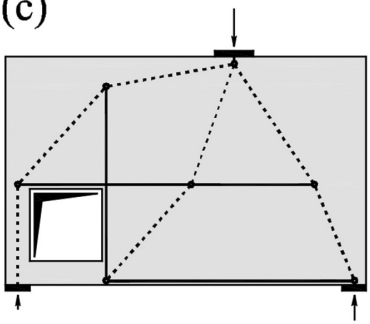

(b)

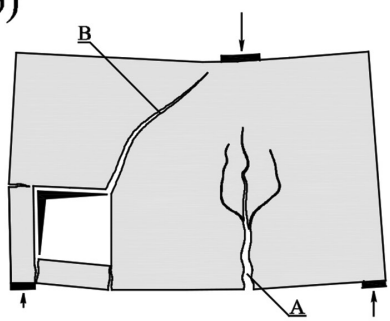

(d)

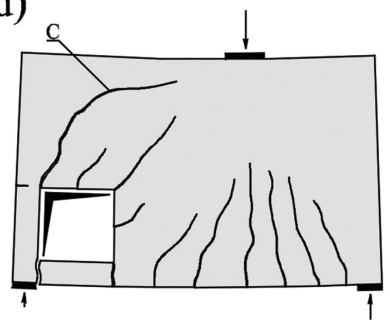

Fig. 6-Potential problems for simple load-carrying models: (a) strut-and-tie model with primary tension tie above opening; (b) corresponding cracking pattern; (c) load-carrying model with one vertical tie anchored within concrete element; and (d) corresponding cracking pattern. ${ }^{28}$

(a)

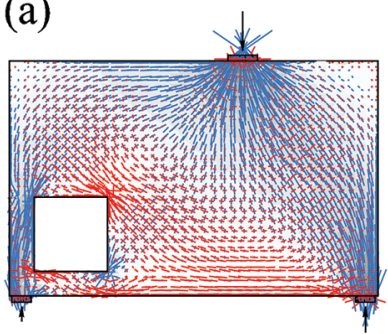

(b)

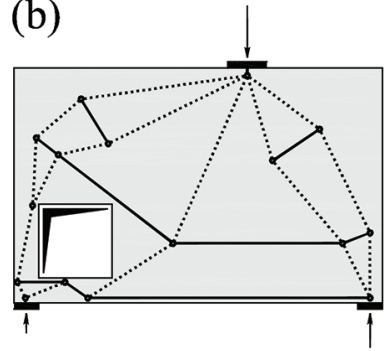

Fig. 7-Development of strut-and-tie models on basis of elastic-uncracked stress fields: (a) elastic-uncracked stress field of investigated element; and (b) corresponding strutand-tie model.

(a)

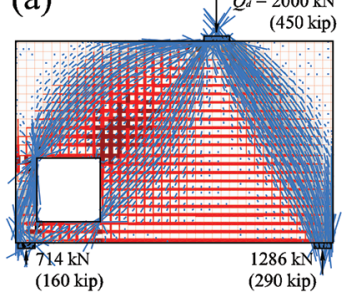

(b)

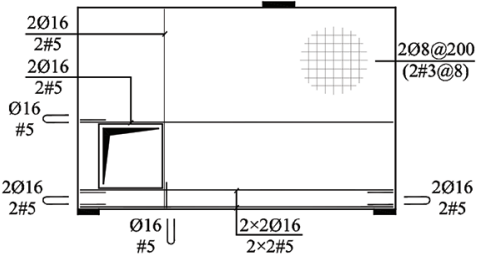

Fig. 8-Elastic-plastic stress fields: (a) resulting EPSF for investigated member; and (b) calculated reinforcement.

CTT or CCT (where C refers to compression and $\mathrm{T}$ to tension) can be used, provided that the minimum angles between the struts and the ties and the values of coefficient $\eta_{\varepsilon}$ previously discussed are respected. CCC nodes can be used without any restriction.

- The strut-and-tie model has to consider that compression in concrete tends to occupy all available space following the St-Venant's principle. ${ }^{13}$ This is particularly significant with respect to the introduction of concentrated loads. ${ }^{25,27}$ It should also be considered for the

anchorage of tension ties. For instance, Fig. 6(c) presents a load-carrying model where the vertical tension tie is anchored within the element and not at its edge. As experimentally shown by Maxwell and Breen, ${ }^{28}$ this may lead to development of wide cracks on top of the anchorage region because the strut tends to occupy all available concrete (unreinforced region of anchorage of the vertical tie; refer to region "C" in Fig. 6(d)), which cracks in an uncontrolled manner.

\section{Load-carrying models inspired on elastic uncracked stress field of member}

A classical approach to development of strut-and-tie models was early investigated by Leonhardt and Walther ${ }^{12}$ and later refined by Schlaich et al. ${ }^{14}$ The approach considers the elastic uncracked stress field of a member (Fig. 7(a)) and arranges the reinforcement following the location, the direction, and the intensity of the tensile stresses (Fig. 7(b)). This method provides, other than a safe design, generally satisfactory behavior at SLS (cracking) because the deformation of the zones in tension controlled by a reinforcement. This approach, however, presents a number of shortcomings:

- The location and arrangement of the reinforcement is not decided by the designer. Usually, inclined bars result from the elastic stress field, which are very efficient for control of cracking but might be unpractical for placing (refer to Fig. 7(b)).

- The method leads potentially to TTT nodes (for instance, for corner frames with opening moments ${ }^{29}$ ) and requires modification of the strut-and-tie model.

- The amount of required reinforcement is not necessarily the minimum required for statical reasons. This is, for instance, the case when imposed strains are considered as actions (imposed strains can be dissipated provided that the member has sufficient ductility). Also, this results from the location of the tension ties, which are generally more efficient when placed at the outermost fiber of the member respecting concrete cover, to maximize the lever arms rather than at the resultant of the uncracked stress field.

\section{Load-carrying models inspired on cracked stress field of member}

More suitable stress fields that can be used to develop consistent load-carrying models refer to those accounting for the cracked behavior of concrete. To that purpose, advanced constitutive material models can be used. Alternatively, Fernández Ruiz and Muttoni ${ }^{18}$ proposed to develop simple elastic-plastic stress fields (EPSFs) accounting for the cracked behavior of concrete (Fig. 3(c)). This can be seen as a simplification of more general constitutive models and leads to suitable results when sufficient transverse reinforcement is available to avoid crack localization. ${ }^{18}$ Figure 8 (a) depicts the corresponding EPSF for the previously investigated case of a deep beam with an opening. The EPSF indicates the location of the compression fields, fans, and forces carried by the reinforcement. Although strut-and-tie models (or rigid-plastic stress fields) can be developed on that basis, ${ }^{18}$ the results of the EPSF can be directly used for the 
design and optimization of the reinforcement ${ }^{30}$ because they are already a licit stress field. An approach to optimize the reinforcement layout and amount has been also presented by Fernández Ruiz and Muttoni. ${ }^{18}$ It consists of starting with a preliminary analysis where a minimum reinforcement for crack control is arranged in the member $\left(A_{s i, m i n}\right)$ with the geometry and location preferred by the designer; for instance, the orthogonal welded wire reinforcement shown in Fig. 8(a). The reinforcement is considered to behave elastic and the concrete is considered to behave with no tensile strength (cracked behavior). From this preliminary analysis, the stresses developed in the various reinforcement bars can be calculated $\left(\sigma_{s i}\right)$. The area of the reinforcements $\left(A_{s i}\right)$ can thus be updated for the next step to respect the yield condition of the reinforcement

$$
A_{s i, j}=A_{s i, j-1} \frac{\sigma_{s i}}{f_{y i}} \geq A_{s i, m i n}
$$

where $f_{y i}$ refers to the yield strength of the reinforcement; and $i$ and $j$ refer to the iteration number $(j=2$ is the first iteration; $j=1$ is the first step corresponding to $A_{s i \text {, min }}$ ). With the updated reinforcement amounts, the EPSF analyses can be repeated until the solution converges to a final reinforcement layout (Fig. 8(b); calculations performed for a design yield strength of the tension reinforcement equal to $435 \mathrm{MPa}$ [63 ksi]), where the required diameter of the bars is slightly increased to round them to available commercial values (which introduces a slight strength reserve). The required number of iterations to attain the final solution is quite low, and the method is robust for its practical application ${ }^{31}$ (there is no need to perform further rigid-plastic analyses). In addition, because the minimum amount of reinforcement $\left(A_{s i, \min }\right)$ is directly considered in the first step (and is not simply added at the end), its contribution can be considered for calculation of the failure load and this leads to potential savings in the total amount of reinforcement. Additionally, taking advantage of the compatibility conditions of the EPSF, the final reinforcement layout can be also analysed at serviceability limit state, both for deflections and cracking.

\section{ASSESSMENT OF EXISTING STRUCTURES}

Structural assessment is usually performed when the loads acting on a structure are increased, deficiencies related to design or construction are known, deterioration occurs, or when current code provisions are more severe than the ones used for the original design of the structure. Retrofitting of existing structures is, however, expensive and complicated and thus the assessment of existing structures has to look for avoiding or minimizing them. Typically, this can be performed following a levels-of-approximation approach, ${ }^{4}$ starting with simple load-carrying models (or a combination of them) and refining them whenever insufficient strength is obtained.

It should also be noted that, during design, even using rational approaches, as previously presented, some elements are not considered within the primary load-carrying models. This is usually the case of the minimal amount of reinforcement for crack control. This additional reinforcement should nevertheless be considered as part of the load-carrying mechanism for an assessment as it increases the strength of the member in a potentially non-negligible manner. ${ }^{32}$ In addition, design based on lower-bound solutions according to limit analysis (as stress fields or strut-and-tie models) implies that more efficient load-carrying models may develop within the member for the available geometry and reinforcement.

In case conventional analyses do not allow ensuring sufficient strength with respect to the design actions, refined estimates of the strength are required. In this case, the best lower-bound solution that can be selected is the exact solution according to limit analysis, which provides the maximum strength of all possible lower-bounds. Different techniques can be used to obtain the exact solution. In the following, two approaches will be examined: the former based on rigid-plastic stress fields and the latter based on elastic-plastic stress fields. To that aim, the strength of the previous element (Fig. 4(a)) will be assessed with each approach for the reinforcement layout designed according to the strut-and-tie inspired on simple load-carrying models (Fig. 4(f)).

\section{Development of exact solutions based on rigid- plastic stress fields and mechanisms}

The use of rigid-plastic stress fields combined with mechanisms for the search of an exact solution has been discussed by Muttoni et al. ${ }^{33}$ It can be performed by first selecting a licit collapse mechanism (upper-bound solution) whose free bodies are separated by discrete cracks and concrete hinges (refer to Fig. 9(a)). According to the upper-bound approach of rigid-plastic limit analysis (mechanism), all reinforcement crossing the cracks reaches its yield strength so that tie forces at ultimate limit state can be calculated easily (Fig. 9(b), where concrete is assumed to carry no tensile stress). The contact zones between the free bodies can be considered compression zones where the struts or nodal regions develop (Fig. 9(c) through (e)).

There are basically two methods to calculate the loadcarrying capacity related to a given mechanism. The first one is based on the principle of virtual work, where the work of external loads (sum of scalar product of external forces and related displacements) is equal to the internal plastic dissipation (sum of all reinforcement yielding forces and concrete forces multiplied by their elongation or shortenings). In the second method, the equilibrium of every free body is treated separately.

With respect to the second method, solving the equilibrium equations of every free body can be performed in an easy manner by following an iterative procedure. Alternatively, the contact forces between the free bodies can be determined without the need of performing any iterations by solving a system of equations relating all implied variables. Details and implementation of such procedures is thoroughly explained in Appendix A* for the investigated wall presented in Fig. 4(f) (refer also to Table 3 for results).

\footnotetext{
*The Appendix is available at www.concrete.org/publications in PDF format, appended to the online version of the published paper. It is also available in hard copy from $\mathrm{ACI}$ headquarters for a fee equal to the cost of reproduction plus handling at the time of the request.
} 

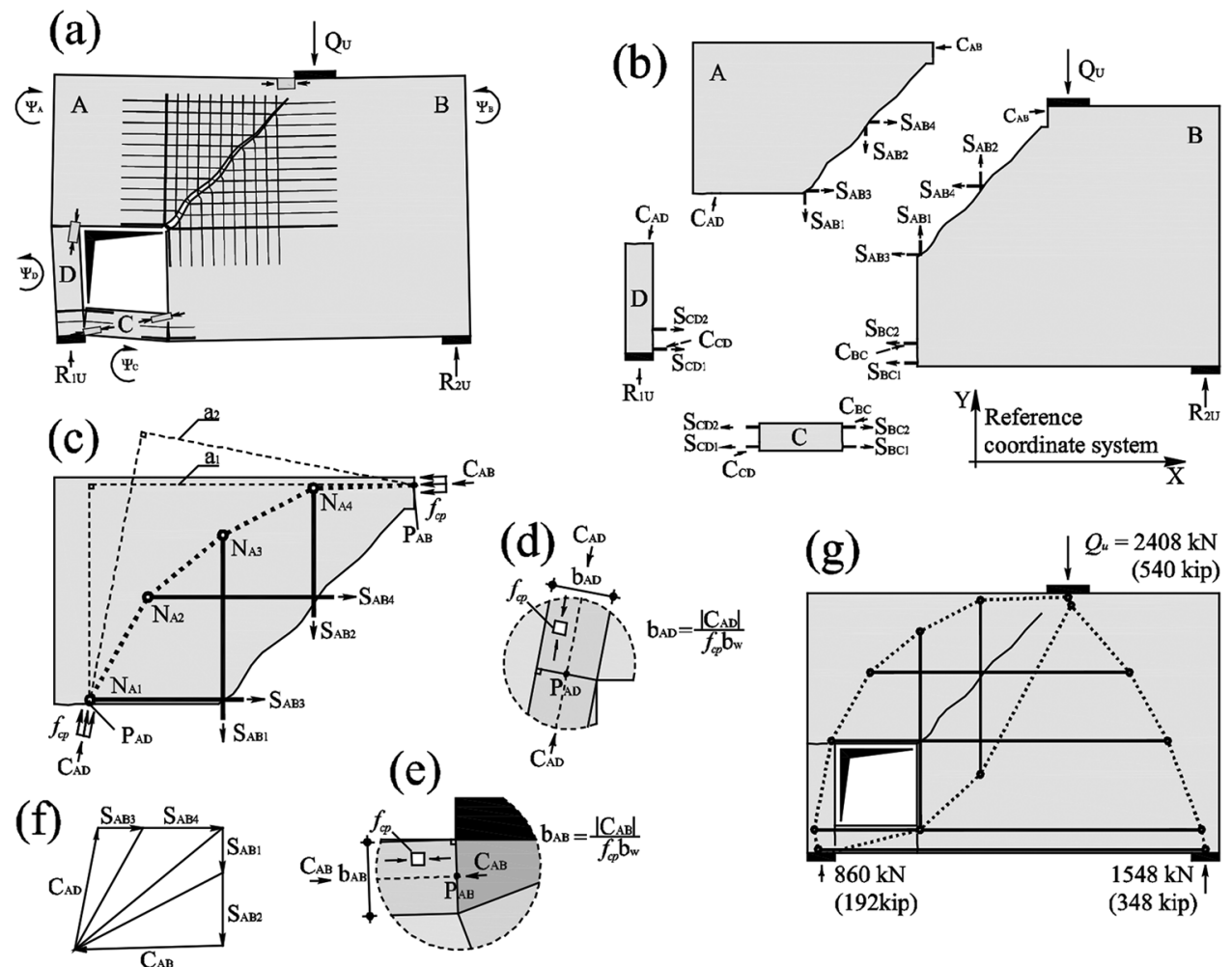

Fig. 9-Assessment of strength using rigid-plastic mechanisms (values provided in Table 3): (a) failure mechanism; (b) and (c) analysis of rigid bodies of mechanism; (d) and (e) analysis of critical struts; $(f)$ Cremona diagram and thrust line inside rigid body; and (g) corresponding strut-and-tie model.

The load-carrying capacity $Q_{R}$ of the selected mechanism (Fig. 9(a)), calculated by any of the previous procedures, is still not proven to correspond to that of the exact solution according to limit analysis, as other potential mechanisms (Fig. 10(a), for instance) can develop. As this procedure is based on the upper-bound theorem of limit analysis, the exact load-carrying capacity $Q_{R \text {,exact }}$ could be lower than the calculated value $Q_{R}$. An interesting approach to verify if the selected mechanism corresponds to the exact solution can be performed by combining both theorems of limit analysis. As stated by Drucker?: "Agreement of upper and lower bounds proves that the load carrying capacity is exactly halved." This procedure can be seen as an optimization where the criterion is related to the load-carrying capacity.

In the current example, this can be done by investigating the internal equilibrium of all bodies as well as the strengths of steel and concrete elements using strut-and-tie or stress fields models. This is, for instance, shown in Fig. $9(\mathrm{~g})$ for the reinforcement layout of Fig. 4(f) (inspired by simple load-carrying models). A suitable strategy can consist in developing, within the free bodies, the previously calculated internal forces acting on the edges of the free bodies. Starting from force $\mathrm{C}_{\mathrm{AD}}$ on concrete body A (Fig. 9(b)), the first node $\mathrm{N}_{\mathrm{A} 1}$ can be set at the intersection with the lower reinforcement, whose force $\mathrm{S}_{\mathrm{AB} 3}$ deviates the strut. Nodal equilibrium can be solved analytically or graphically using force diagrams. In this case, the second approach allows following the strut and its deviation at every reinforcement, until the internal force $\mathrm{C}_{\mathrm{AB}}$ on the opposite side is reached. Provided that the compression fields remain within concrete
(Fig. 9(g)), a licit solution will have been obtained. On the contrary, when the calculated stress field leads to compression forces developing where no concrete is available (Fig. 10(b)), the selected mechanism does not correspond to the exact solution and the ultimate strength is overestimated $\left(Q_{u}=3201 \mathrm{kN}[720 \mathrm{kip}]\right.$ in Fig. 10(b)). In this case, other mechanisms have to be investigated.

The obtained result (Fig. 9(g)) for the reinforcement layout of Fig. 4(f) leads to a failure load of $2408 \mathrm{kN}$ (540 kip). This result is above the original design load of $2000 \mathrm{kN}$ (450 kip) and shows a strength reserve of $20 \%$. This is due to the fact that: 1) the selected strut-and-tie model for design of the main reinforcement is a lower bound; 2) the necessary reinforcement was rounded (increased) to the next available commercial diameter; and 3) the minimum reinforcement amount was not considered to contribute to its strength (contrary to the EPSF approach for design shown in Fig. 8).

\section{Development of exact solutions based on elastic- plastic stress fields}

Despite the generality of the approach explained in the previous section, obtaining a solution following a rigidplastic approach might be time-consuming in some cases. A suitable alternative to overcoming this shortcoming is the development of elastic-plastic stress fields that can be used to obtain exact solutions according to limit analysis in an automated and time-efficient manner. This type of stress field ${ }^{18}$ considers an elastic behavior for concrete and steel (following their elastic stiffness) until the plastic plateau is reached. No tensile stresses are also considered for 
Table 3-Forces acting in free bodies in Fig. 9

\begin{tabular}{|c|c|c|c|c|c|}
\hline \multirow{3}{*}{$\begin{array}{l}\text { Free } \\
\text { body }\end{array}$} & \multirow{3}{*}{$\begin{array}{l}\text { Force } \\
\text { name }\end{array}$} & \multicolumn{4}{|c|}{ Forces } \\
\hline & & \multicolumn{2}{|c|}{$\begin{array}{c}\text { First iteration } \\
\text { (equilibrium not fulfilled) }\end{array}$} & \multicolumn{2}{|c|}{$\begin{array}{c}\text { Final iteration } \\
\text { (equilibrium fulfilled) }\end{array}$} \\
\hline & & $\mathrm{kN}$ & kip & $\mathrm{kN}$ & kip \\
\hline \multirow{8}{*}{ A } & $\mathrm{S}_{\mathrm{AB} 1}$ & -273 & -61 & -273 & -61 \\
\hline & $\mathrm{S}_{\mathrm{AB} 2}$ & -437 & -98 & -437 & -98 \\
\hline & $\mathrm{S}_{\mathrm{AB} 3}$ & 273 & 61 & 273 & 61 \\
\hline & $\mathrm{S}_{\mathrm{AB} 4}$ & 481 & 108 & 481 & 108 \\
\hline & $\mathrm{C}_{\mathrm{AB}, \mathrm{X}}$ & -754 & -169 & -897 & -201 \\
\hline & $\mathrm{C}_{\mathrm{AB}, \mathrm{Y}}$ & 71 & 16 & -28 & -6 \\
\hline & $\mathrm{C}_{\mathrm{AD}, \mathrm{X}}$ & 0 & 0 & 143 & 32 \\
\hline & $\mathrm{C}_{\mathrm{AD}, \mathrm{Y}}$ & 639 & 143 & 738 & 165 \\
\hline \multirow{14}{*}{ B } & $\mathrm{S}_{\mathrm{AB} 1}$ & 273 & 61 & 273 & 61 \\
\hline & $\mathrm{S}_{\mathrm{AB} 2}$ & 437 & 98 & 437 & 98 \\
\hline & $\mathrm{S}_{\mathrm{AB} 3}$ & -273 & -61 & -273 & -61 \\
\hline & $\mathrm{S}_{\mathrm{AB} 4}$ & -481 & -108 & -481 & -108 \\
\hline & $\mathrm{S}_{\mathrm{BC} 1}$ & -295 & -66 & -295 & -66 \\
\hline & $\mathrm{S}_{\mathrm{BC} 2}$ & -295 & -66 & -295 & -66 \\
\hline & $\mathrm{C}_{\mathrm{AB}, \mathrm{X}}$ & 754 & 169 & 897 & 201 \\
\hline & $\mathrm{C}_{\mathrm{AB}, \mathrm{Y}}$ & -71 & -16 & 28 & 6 \\
\hline & $\mathrm{C}_{\mathrm{BC}, \mathrm{X}}$ & 590 & 132 & 447 & 100 \\
\hline & $\mathrm{C}_{\mathrm{BC}, \mathrm{Y}}$ & 0 & 0 & 122 & 27 \\
\hline & $\mathrm{R}_{2 \mathrm{U}, \mathrm{X}}$ & 0 & 0 & 0 & 0 \\
\hline & $\mathrm{R}_{2 \mathrm{U}, \mathrm{Y}}$ & 1150 & 259 & 1548 & 348 \\
\hline & $\mathrm{Q}_{\mathrm{U}, \mathrm{X}}$ & 0 & 0 & 0 & 0 \\
\hline & $\mathrm{Q}_{\mathrm{U}, \mathrm{Y}}$ & -1789 & -402 & -2408 & -540 \\
\hline \multirow{8}{*}{$\mathrm{C}$} & $\mathrm{S}_{\mathrm{CD} 1}$ & -295 & -66 & -295 & -66 \\
\hline & $\mathrm{S}_{\mathrm{CD} 2}$ & -295 & -66 & -295 & -66 \\
\hline & $\mathrm{S}_{\mathrm{BC} 1}$ & 295 & 66 & 295 & 66 \\
\hline & $\mathrm{S}_{\mathrm{BC} 2}$ & 295 & 66 & 295 & 66 \\
\hline & $\mathrm{C}_{\mathrm{BC}, \mathrm{X}}$ & -590 & -132 & -447 & -100 \\
\hline & $\mathrm{C}_{\mathrm{BC}, \mathrm{Y}}$ & 0 & 0 & -122 & -27 \\
\hline & $\mathrm{C}_{\mathrm{CD}, \mathrm{X}}$ & 590 & 132 & 447 & 100 \\
\hline & $\mathrm{C}_{\mathrm{CD}, \mathrm{Y}}$ & 0 & 0 & 122 & 27 \\
\hline \multirow{8}{*}{$\mathrm{D}$} & $\mathrm{S}_{\mathrm{CD} 1}$ & 295 & 66 & 295 & 66 \\
\hline & $\mathrm{S}_{\mathrm{CD} 2}$ & 295 & 66 & 295 & 66 \\
\hline & $\mathrm{C}_{\mathrm{AD}, \mathrm{X}}$ & 0 & 0 & -143 & -32 \\
\hline & $\mathrm{C}_{\mathrm{AD}, \mathrm{Y}}$ & -639 & -144 & -738 & -165 \\
\hline & $\mathrm{C}_{\mathrm{CD}, \mathrm{X}}$ & -590 & -132 & -447 & -100 \\
\hline & $\mathrm{C}_{\mathrm{CD}, \mathrm{Y}}$ & 0 & 0 & -122 & -27 \\
\hline & $\mathrm{R}_{1 \mathrm{U}, \mathrm{X}}$ & 0 & 0 & 0 & 0 \\
\hline & $\mathrm{R}_{1 \mathrm{U}, \mathrm{Y}}$ & 639 & 144 & 860 & 192 \\
\hline
\end{tabular}

concrete. This type of stress field, because it accounts for the conditions of a lower-bound solution (equilibrium and yield conditions) as well as the compatibility of displacements (stress field calculated on the basis of a displacement
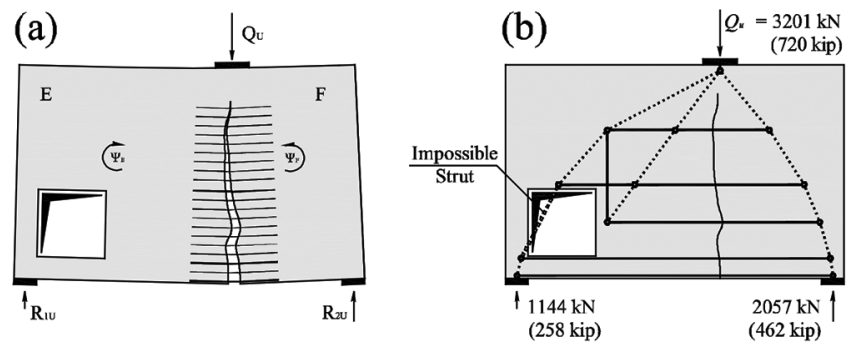

Fig. 10-Analysis of other potential failure mechanisms: (a) assumed cracks and kinematics; and (b) corresponding (illicit) strut-and-tie model.

field), allows for obtaining exact solutions in an automated manner. This is, for instance, shown in Fig. 11, where the elastic-plastic stress field (Fig. 11(a)) and its corresponding displacement field (Fig. 11(b)) are presented for the investigated member for the reinforcement layout of Fig. 4(f). The failure load results $2680 \mathrm{kN}$ (603 kip). The difference with respect to the mechanism calculated using the rigid-plastic approach can mostly be explained by the vertical reinforcement of the column at the left-hand side of the opening (which was neglected for the rigid-plastic analysis) and by the role of the compression reinforcement (also neglected for the rigid-plastic analysis shown previously). It can also be noted that the computed failure mechanism (Fig. 11(b)) nicely agrees with the selected mechanism at failure for the rigid-plastic analysis.

\section{VALIDATION}

Many works can be found on the applicability of limit analysis to reinforced concrete showing its generality and consistency (refer, for instance, to Reference 6). This is verified provided that no strain localization happens (minimum amount of reinforcement required) and that the material and structural member have a ductile behavior. In other cases, theories accounting for crack localization ${ }^{34}$ or crushing of concrete prior to yielding of the reinforcement ${ }^{6}$ are to be used.

To investigate on the accuracy of EPSF (as a predictor of exact solutions according to limit analysis), Fig. 12 presents a comparison of the results of this tool against 150 available test data (prestressed and reinforced beams, corner frames, and walls with and without openings). The assessment of the strength of the tests is performed by developing an EPSF for each element ${ }^{18}$ (the behavior of steel is assumed to be elastic-plastic with no strain hardening). The results of EPSF show consistent results for all investigated cases. The average ratio of the actual failure load to predicted is 1.05 and presents a fairly low value of the coefficient of variation $(10 \%$, considering all the tests). Details for each series on the specimens, failure mode, and predicted failure loads can be found in Table B1 (refer to Appendix B) of this paper. The results, shown in Fig. 12, show no trend for the most significant mechanical parameters (compressive strength, level of axial load of beams, and longitudinal and transversal reinforcement ratios) and validate the generality and accuracy of the approach. 

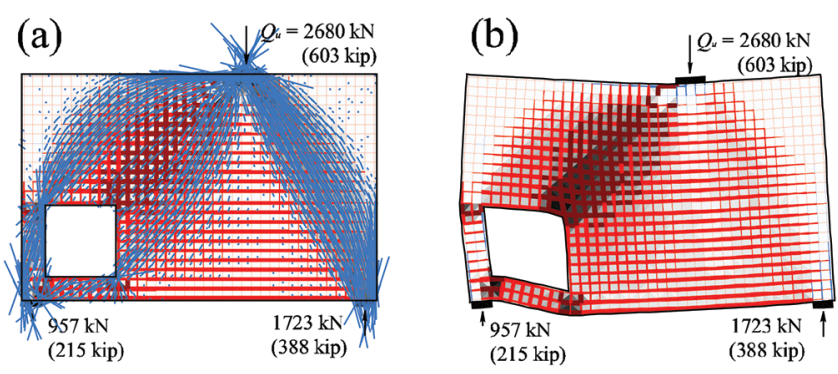

Fig. 11-Assessment using EPSF: (a) resulting stress field; and (b) calculated displacement field at failure (mechanism).
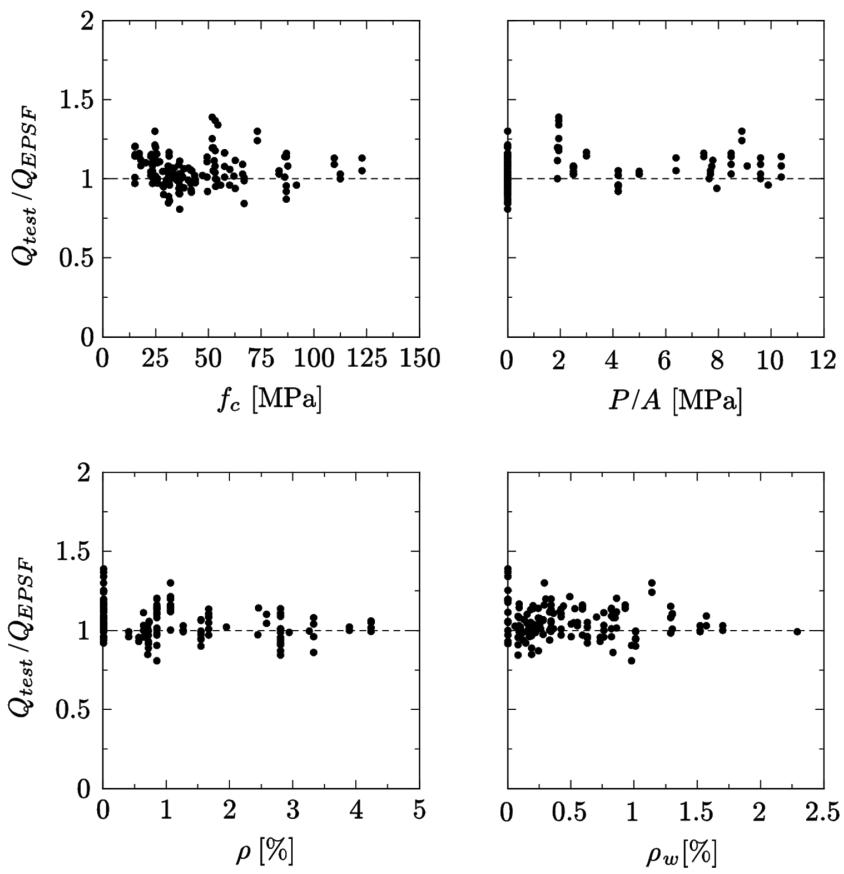

Fig. 12-Assessment of test results using EPSF: comparison of actual strength and predictions as a function of compressive strength $\left(\mathrm{f}_{\mathrm{c}}\right)$, axial force level (P/A) longitudinal reinforcement ratio $(\rho)$ and transverse reinforcement ratio $\left(\rho_{\mathrm{w}}\right)$ (tests detailed in Table B1, average of $\mathrm{Q}_{\mathrm{test}} / \mathrm{Q}_{\mathrm{EPSF}}=1.05$, $\mathrm{CoV}=10 \%)$. (Note: $1 \mathrm{MPa}=145 \mathrm{psi}$.)

\section{CONCLUSIONS}

This paper discusses suitable approaches for the design and assessment of structural concrete members by using stress fields and strut-and-tie models. Its most significant conclusions are summarized as follows:

1. Design and assessment of structural concrete can be performed on the basis of limit analysis provided that its hypotheses (mostly avoidance of strain localization which leads to brittle behavior) are respected. However, design and assessment should not necessarily be performed following the same strategies. For design, simple load-carrying models in equilibrium with the external actions and respecting the yield conditions of the materials are usually suitable. From the various possibilities, those leading to a better behavior at serviceability limit state and corresponding to simple reinforcement layouts are the best choices. For assessment of existing critical structures, the estimate of the strength has to be refined. To that aim, developing exact solutions according to limit analysis is a suitable approach (they provide the highest strength of all potential safe estimates). This allows avoiding unnecessary strengthening of existing structures or minimizing it. Serviceability issues in these cases can be checked directly on the existing structure in case the actions remain unchanged.

2. Stress fields and strut-and-tie models are both based on the lower-bound theorem of limit analysis and can be efficiently used for design of new structures. Each method presents a number of advantages. Stress fields are most suited for detailing, checking of concrete behavior, and providing a better estimate of the location of the struts. Strutand-tie models are simpler for developing calculation of the required reinforcement.

3. Exact solutions can be developed manually in an iterative manner by considering a failure mechanism and by calculating the corresponding rigid-plastic stress field inside. In case the compression field cannot develop within the available geometry, the failure mechanism has to be adapted accordingly.

4. Automated procedures based on EPSFs are suitable for both design of new structures and for assessment of existing structures. EPSFs satisfy equilibrium and yield conditions (lower-bound solution), but also compatibility conditions (upper-bound solution, as at ultimate, a mechanism develops). As a consequence, they can be used to obtain exact solutions according to limit analysis in an automated manner. This tool has the further advantage of accounting for all potential load-carrying actions, particularly of minimum reinforcement, and to allow refined estimates of the strength parameters of concrete (as the reduction on the concrete strength due to transverse cracking).

5. The EPSF method allows calculating directly the load-carrying capacity of an existing structure and thus assessing its strength. The EPSF method can also be used for designing new structures according to a simple iterative procedure described within this paper.

6. A systematic comparison of exact solutions according to limit analysis to available test data (150 tests) shows consistent results for a wide number of geometries (such as dapped end beams, deep beams, prestressed girders, corner frames, and walls) and failure modes (including shear, bending, and detailing), providing accurate estimates of their strength with a low scatter of the predictions, and proving the consistency and generality of the approach.

\section{AUTHOR BIOS}

ACI member Aurelio Muttoni is a Professor and Head of the Structural Concrete Laboratory at Ecole Polytechnique Fédérale de Lausanne (EPFL), Lausanne, Switzerland. Muttoni received the ACI Chester Paul Siess Award for Excellence in Structural Research in 2010 and was a co-recipient of the ACI Wason Medal for Most Meritorious Paper in 2014. His research interests include the theoretical bases of the design of reinforced concrete structures, shear and punching shear, fiber-reinforced high-strength concrete, soil-structure interaction, and the conceptual design of bridges.

Miguel Fernández Ruiz is a Lecturer and Senior Scientist at EPFL. His research interests include the serviceability behavior of structures, bond, shear and punching shear, and the modeling of structural concrete using stress fields.

Filip Niketić is a Research Assistant and PhD Candidate at EPFL. He was a co-recipient of the ACI Wason Medal for Most Meritorious Paper in 2014. 
His research interests include the applicability of stress fields for design and assessment of structural concrete.

\section{REFERENCES}

1. fib Model Code for Concrete Structures 2010, Fédération Internationale du Béton, Lausanne, Switzerland, 2013, 434 pp.

2. ACI Committee 437, "Strength Evaluation of Existing Concrete Buildings (ACI 437R-03)," American Concrete Institute, Farmington Hills, MI, 2003, $28 \mathrm{pp}$

3. ACI Committee 364, "Guide for Evaluation of Concrete Structures before Rehabilitation (ACI 364.1R-07)," American Concrete Institute, Farmington Hills, MI, 2007, 18 pp.

4. Muttoni, A., and Fernández Ruiz, M., "Levels-of-Approximation Approach in Codes of Practice," Structural Engineering International, V. 22, No. 2, 2012, pp. 190-194. doi: 10.2749/101686612X13291382990688 5. SIA 269:2011, "Existing Structures - Bases," Swiss Society of Engineers and Architects, Zurich, Switzerland, 2011, 28 pp.

6. Nielsen, M. P., and Hoang, L. C., Limit Analysis and Concrete Plasticity, third edition, CRC Press, Boca Raton, FL, 2011, 796 pp.

7. Drucker, D. C., On Structural Concrete and the Theorems of Limit Analysis, International Association for Bridge and Structural Engineering, Zürich, Switzerland, 1961, 36 pp.

8. Muttoni, A.; Schwartz, J.; and Thürlimann, B., Design of Concrete Structures with Stress Fields, Birkhäuser, Basel-Boston-Berlin, Switzerland, 1997, $143 \mathrm{pp}$.

9. Chen, W.-F., and Han, D.-J., Plasticity for Structural Engineers, J. Ross Publishing, Fort Lauderdale, FL, 2007, 255 pp.

10. Ritter, W., "Die Bauweise Hennebique," Schweizerische Bauzeitung, V. 33, No. 7, 1899, pp. 41-61.

11. Mörsch, E., Der Eisenbetonbau, seine Theorie und Anwendung, third edition, Verlag von Konrad Wittwer, Hamburg, Germany, 1908, 376 pp.

12. Leonhardt, F., and Walther, R., Wandartige Träger, Deutscher Ausschuss für Stahlbeton, Berlin, Germany, 1966, 159 pp.

13. Schlaich, J., and Weischede, D., "Ein praktisches Verfahren zum methodischen Bemessen und Konstruieren im Stahlbetonbau," Bulletin d'Information No. 150, Comité Euro-International du Béton, Lausanne, Switzerland, 1982, $163 \mathrm{pp}$.

14. Schlaich, J.; Schäfer, K.; and Jennewein, M., "Toward a Consistent Design of Structural Concrete," PCI Journal, V. 32, No. 3, 1987, pp. 74-150. doi: 10.15554/pcij.05011987.74.150

15. Biondini, F.; Bontempi, F.; and Malerba, P. G., "Stress Path Adapting Strut-and-Tie Models in Cracked and Uncracked R.C. Elements," Structural Engineering \& Mechanics, V. 12, No. 6, 2001, pp. 685-698. doi: 10.12989/sem.2001.12.6.685

16. Gvozdev, A. A., "The Determination of the Value of the Collapse Load for Statically Indeterminate Systems Undergoing Plastic Deformation," International Journal of Mechanical Sciences, V. 1, No. 4, 1960, pp. 322-335. doi: 10.1016/0020-7403(60)90051-5

17. Thürlimann, B.; Marti, P.; Pralong, J.; Ritz, P.; and Zimmerli, B., Anwendung der Plastizitätstheorie auf Stahlbeton, Institut für Baustatik und Konstruction, ETH Zürich, 1983, 252 pp.

18. Fernández Ruiz, M., and Muttoni, A., "On Development of Suitable Stress Fields for Structural Concrete," ACI Structural Journal, V. 104, No. 4, July-Aug. 2007, pp. 495-502.
19. Muttoni, A., Die Anwendbarkeit der Plastizitätstheorie in der Bemessung von Stahlbeton, Birkhäuser Verlag, Institut für Baustatik und Konstruktion, ETH Zürich, Basel, Switzerland, 1990, 176 pp.

20. Vecchio, F. J., and Collins, M. P., "The Modified Compression-Field theory for Reinforced Concrete Elements Subjected to Shear," ACI Journal Proceedings, V. 83, No. 2, Mar.-Apr. 1986, pp. 219-231.

21. Fernández Ruiz, M., and Muttoni, A., "Shear Strength of ThinWebbed Post-Tensioned Beams," ACI Structural Journal, V. 105, No. 3, May-June 2008, pp. 308-317.

22. Rupf, M.; Fernández Ruiz, M.; and Muttoni, A., "Post-Tensioned Girders with Low Amounts of Shear Reinforcement: Shear Strength and Influence of Flanges," Engineering Structures, V. 56, Nov, 2013, pp. 357-371. doi: 10.1016/j.engstruct.2013.05.024

23. Fernández Ruiz, M.; Muttoni, A.; and Gambarova, P., "Relationship between Nonlinear Creep and Cracking of Concrete under Uniaxial Compression," Journal of Advanced Concrete Technology, V. 5, No. 3, 2007, pp. 383-393. doi: 10.3151/jact.5.383

24. Lourenco, M. S., and Almeida, J. F., “Adaptive Stress Field Models: Formulation and Validation," ACI Structural Journal, V. 110, No. 1, Jan.-Feb. 2013, pp. 71-81.

25. Bayrak, O., and Brown, M., "Minimum Transverse Reinforcement for Bottle-Shaped Struts," ACI Structural Journal, V. 103, No. 6, Nov.-Dec. 2006, pp. 813-822.

26. Grob, J., and Thürlimann, B., "Ultimate Strength and Design of Reinforced Concrete Beams under Bending and Shear," IABSE, V. 36, 1976, pp. $105-120$.

27. Brown, M. D.; Sankovich, C. L.; Bayrak, O.; and Jirsa, J. O., "Behavior and Efficiency of Bottle-Shaped Struts," ACI Structural Journal, V. 103, No. 3, May-June 2006, pp. 348-354.

28. Maxwell, B. S., and Breen, J. E., "Experimental Evaluation of Strutand-Tie Model Applied to Deep Beam with Opening," ACI Structural Journal, V. 97, No. 1, Jan.-Feb. 2000, pp. 142-149.

29. Campana, S.; Fernández Ruiz, M.; and Muttoni, A., "Behaviour of Nodal Regions of Reinforced Concrete Frames Subjected to Opening Moments and Proposals for their Reinforcement," Engineering Structures, V. 51, 2013, pp. 200-210. doi: 10.1016/j.engstruct.2013.01.029

30. Najafian, H. A., and Vollum, R. L., "Optimising Reinforcement Design in D Regions Using Non-Linear Finite-Element Analysis," Magazine of Concrete Research, V. 65, No. 4, 2013, pp. 234-247. doi: 10.1680/ macr. 12.00063

31. Kostic, N., "Topologie des Champs de Contraintes pour le Dimensionnement des Structures en Béton Armé," PhD thesis, Ecole Polytechnique Fédérale de Lausanne, Lausanne, Switzerland, 2009, 235 pp.

32. Kuchma, D.; Yindeesuk, S.; Nagle, T.; Hart, J.; and Lee, H. H., "Experimental Validation of Strut-and-Tie Method for Complex Regions," ACI Structural Journal, V. 105, No. 5, Sept.-Oct. 2008, pp. 578-589.

33. Muttoni, A.; Kostic, N.; and Fernández Ruiz, M., "Discussion of paper "Factors Affecting Strength of Elements Designed Using Strutand-Tie Models," ACI Structural Journal, V. 105, No. 2, Mar.-Apr. 2008, pp. 233-237.

34. Muttoni, A., and Fernández Ruiz, M., "Shear Strength of Members without Transverse Reinforcement as Function of Critical Shear Crack Width," ACI Structural Journal, V. 105, No. 2, Mar.-Apr. 2008, pp. 163-172. 
